\title{
O consumo e a utilização das sacolas plásticas no Distrito Federal, Brasil, como produto de armazenamento: análise do ambiente em que estão inseridas
}

\author{
Leyna Gimena de Matos Leite*, Ana Karl
}

Instituto CEUB de Pesquisa e Desenvolvimento. Centro Universitário de Brasília. Campus do UniCEUB. SEPN 707/907. Via W 5 Norte. Asa Norte. Brasília-DF, Brasil (CEP 70790-075). *E-mail: leynagimena@gmail.com.

Resumo. No Brasil são produzidos cerca de 3 milhões de toneladas de plástico. Atualmente, $10 \%$ do lixo brasileiro são compostos por sacolas plásticas e cada brasileiro utiliza $19 \mathrm{~kg}$ de sacolas por ano. Para se dimensionar a gravidade da situação ora vivenciada no país, o Estado do Rio de Janeiro consome um bilhão de sacos plásticos por ano e gasta $\mathrm{R} \$ 15$ milhões para dragar rios e tentar retirar os plásticos que provocam danos à natureza. As sacolas distribuídas nos supermercados são produzidas com polietileno de baixa densidade, mais conhecido como plásticofilme, podendo ocasionar prejuízos ao meio ambiente. Neste sentido, o presente estudo busca observar os aspectos socioeconômicos e culturais implantados pelo uso das sacolas plásticas e identificar a política ambiental, bem como a prática de consumo adotado pelos habitantes do Distrito Federal. Assim, foi realizado um estudo de caso através de pesquisa bibliográfica e pesquisa de campo para a análise da questão, onde todos os entrevistados estão cientes dos impactos que são causados pelo uso da sacola tradicional, porém mais de $50 \%$ não se dispõem a pagar pela sacola biodegradável, bem como 33\% disseram descartar os resíduos sólidos de suas casas diariamente e mais de $40 \%$ relatam não ter o hábito de separar o lixo para enviar à reciclagem. Estes resultados mostram que a utilização das sacolas plásticas acontece por uma questão cultural e de comodidade e a maioria se predispõem ao uso de alternativas diferentes ao da sacola comum.

Palavras-chave: Logística reversa; Desenvolvimento sustentável; Sacola plástica; Políticas ambientais.

Abstract. Consumption and use of plastic bags in Distrito Federal, Brazil, as a storage product: Analysis of the environment in which they are inserted. About 3 million tons of plastic are produced in Brazil. Currently, $10 \%$ of Brazilian waste is made up of plastic bags and each Brazilian uses $19 \mathrm{~kg}$ of bags per year. The State of Rio de Janeiro consumes one billion plastic bags per year and spends $\mathrm{R} \$ 15$ million to dredge rivers and try
Recebido:

23/08/2018

Aceito:

$10 / 11 / 2018$

Publicado:

$31 / 12 / 2018$

Acesso aberto

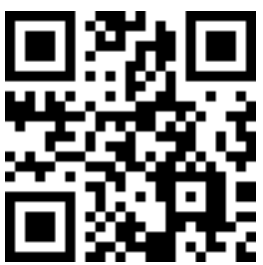

ORCID

(D) 0000-0002-4338-6068 Leyna Gimena de Matos Leite

D 0000-0002-1492-7654 Ana Karl 
to remove plastics that damage nature. The bags distributed in supermarkets are produced with low density polyethylene, better known as plastic-film, and can cause damage to the environment. In this sense, the present study seeks to observe the socioeconomic and cultural aspects implanted using the plastic bags and to identify the environmental policy, as well as the consumption practice adopted by the inhabitants of Distrito Federal. Thus, a case study was carried out through bibliographical and field research to analyze the subject. We found that all the interviewees are aware of the impacts that are caused by the use of the traditional bag, but more than $50 \%$ are not willing to pay for the biodegradable bag as well as 33\% said they discard solid waste from their homes daily and more than $40 \%$ report not having the habit of separating the trash to send to recycling. These results show that the use of plastic bags is a cultural and convenience issue and most are willing to use alternatives to the common bag.

Keywords: Reverse logistic; Sustainable development; Plastic bag; Environmental policies.

\section{Introdução}

No início do século XX foram desenvolvidos novos tipos de materiais denominados plásticos, que aos poucos foram cada vez mais utilizados na fabricação dos mais variados objetos (Piatti e Rodrigues, 2005). A palavra "plástico" deriva do grego plastikos, "próprio para ser moldado ou modelado" e de acordo com o Dicionário de Polímeros (Cangemi, 2005), plástico é o "termo geral dado a materiais macromoleculares que podem ser moldados por ação de calor e/ou pressão" (Cangemi, 2005). Sua versatilidade é tamanha que, desde então, eles vêm provocando mudanças no consumo, e em consequência, no estilo de vida das pessoas (Piatti e Rodrigues, 2005).

A origem do plástico está registrada por volta de 1862, quando o inglês Pakers apresentou as primeiras amostras do que podemos considerar o antecessor da matéria-plástica, em uma exposição internacional de Londres (Saldanha, 2011).

Já em1920 Staudinger propõe a ideia de que os polímeros são constituídos de moléculas em forma de longas cadeias formadas a partir de moléculas menores, por meio da polimerização. (Saldanha, 2011). Nos anos 1930 nasceu o poliestireno, que tem como material base o eteno e o benzeno. Mas sua produção comercial só foi iniciada em 1936, na Alemanha (Saldanha, 2011).

A Bakol S.A., a primeira fábrica de poliestireno, foi inaugurada em São Paulo, em 1949 (Saldanha, 2011). Iniciou-se, então, a produção comercial do poliestireno de alto impacto. No início dos anos 1960, F. H. Lambert desenvolveu o processo para moldagem de poliestireno expandido (Saldanha, 2011).

O plástico substituiu com vantagens uma série de matérias-primas utilizadas pelo homem há milhares de anos, como vidro, madeira, algodão, celulose e metais. Além disso, ao substituir matérias-primas de origem animal, como couro, lã e marfim, possibilitou o acesso a bens de consumo pela população de baixa renda. 0 material já fazia parte do cotidiano das pessoas na década de 1940 (Saldanha, 2011). Tal mudança ocorreu de forma progressiva, alterando a forma e estrutura dos objetos que o ser humano 
estava acostumado a manusear em seu dia-a-dia (Saldanha, 2011).

Por outro lado, o plástico, material escolhido por sua diversidade de aplicações, é também um problema ao final da vida útil dos produtos em que é empregado, especialmente sacolas plásticas e outras formas de embalagens. As possibilidades de produção e consumo que lhes é inerente permitem que persista no ambiente durante muitos anos, e seu baixo custo torna-o altamente descartável (Viana, 2010). Além disso, para que haja crescimento econômico em países cujo modelo de desenvolvimento parte de uma visão capitalista, o consumismo é notório e o desperdício também.

Para a produção das sacolas plásticas usadas nos supermercados, utiliza-se como matéria-prima o plástico filme, este produzido a partir de uma resina chamada Polietileno de Baixa Densidade (conhecido também como "PEBD"). Em nosso país são produzidas em média 210 mil toneladas anuais de plástico filme, representando $9,7 \%$ de todo o lixo do Brasil (Fabro et al., 2007).

Viana (2010) explicita em seu estudo que existem dados estimando que "o uso das sacolas plásticas, em unidades, se aproxime hoje em um milhão por minuto, quase 1,5 bilhão por dia ou mais de 500 bilhões por ano". Viana (2010) ainda cita em seu estudo que o consumo de plásticos no Brasil encontra-se na casa dos $19 \mathrm{~kg}$ por habitante, por ano, enquanto que nos Estados Unidos e na Europa o consumo é de cerca de $100 \mathrm{~kg}$ por habitante e $70 \mathrm{~kg}$ por habitante, respectivamente. O País produziu 18 bilhões de sacolas plásticas em 2007, a maioria fabricada com polietileno de baixa densidade, que pode demorar mais de 100 anos para se decompor.

Cerca de um bilhão de sacolas plásticas são distribuídas todo mês pelos supermercados e estabelecimentos congêneres, com média de 66 sacolas por pessoa, sendo que quase $80 \%$ delas viram sacos de lixo e vão parar nos aterros sanitários e lixões, impedindo a passagem da água e dificultando a decomposição dos detritos e a drenagem hídrica urbana. (Fabro et al., 2007).

Partindo desta problemática associada a noção de Desenvolvimento Sustentável definida pela Conferência das Nações Unidas, a Rio +20 , onde se prevê a integração entre economia, sociedade e meio ambiente, isto é, a noção de que o crescimento econômico deve levar em consideração a inclusão social e a proteção ambiental, é que nos perguntamos: "podemos viver sem as sacolinhas?”. Crespo (2010) discute esta questão e aponta países ricos e pobres que já foram capazes de banir o uso das sacolas plásticas e exemplos de contra incentivo ao seu uso também já são notórios.

Observa-se que a tendência da legislação ambiental no mundo todo é tornar as empresas cada vez mais envolvidas e responsáveis por todo o ciclo de vida dos seus produtos. Isso representa não só a preocupação com o extrativismo e os resíduos, mas também com o destino de seus produtos após o uso e as consequências geradas por eles no meio ambiente (Santos et al., 2012).

A Irlanda foi o primeiro país a atuar nesse sentido. No ano de 2002 obteve num curto intervalo de tempo mais de $90 \%$ de redução no consumo de sacolas plásticas, com a taxação de imposto sobre as mesmas (Santos et al., 2012). A Nova Zelândia seguiu um modelo de cobrança de impostos semelhante ao irlandês. $\mathrm{Na}$ Austrália, campanhas de redução voluntária resultaram em $34 \%$ de redução no consumo de sacolas plásticas num período de 3 anos (2002-2005). Nesse país, os impactos das sacolas plásticas no meio marinho ajudaram a concretizar as ações da comunidade para reduzir o consumo e descarte irregular das sacolas plásticas (Santos et al., 2012).

No Reino Unido, em 2008, foi implantada a lei sobre mudanças climáticas, a qual incluía a criação de um imposto para redução do uso de sacolas plásticas. Porém, poucos aderiram a meta 
de redução de $25 \%$ em um ano e tem-se o registro de iniciativas anteriores que buscaram aumentar a quantidade de material reciclado e reduzir o peso das sacolas (Santos et al., 2012). Nos estados Unidos, São Francisco foi a primeira cidade a proibir o uso de sacolas plásticas em 2007, sendo o uso de sacolas de papel, a opção adotada. A China é outro país, no qual a distribuição gratuita de sacolas plásticas já foi proibida (Santos et al., 2012).

Considerando a alternativa de produção de sacolas biodegradáveis, a sacola plástica composta por amido de milho, está disponível no mercado para abrigar matéria orgânica e seguir para a compostagem se desfazendo em até 180 dias (Lima et al., 2013). Importante ressaltar que a compostagem é o processo biológico de decomposição e de reciclagem da matéria orgânica contida em restos de origem animal ou vegetal formando um composto (MMA, s/d). É de grande valia, pois proporciona um destino útil aos resíduos orgânicos, evitando sua acumulação em aterros e melhorando a estrutura dos solos (MMA, s/d). A grande barreira está na deficiência do sistema de coleta de lixo do país. Dados de 2014 do Sistema Nacional de Informações de Saneamento (SNIS), do Ministério das Cidades, constataram que o número de casas atendidas por serviços de coleta regular de lixo aumentou entre 2013 e 2014 (Senado Federal, 2016). Porém, o deficit de atendimento, ainda é grande, pois 17,3 milhões de pessoas moram em regiões sem nenhum tipo de coleta, a maior parte em zonas rurais e pequenos municípios (Senado Federal, 2016).

Entretanto a legislação brasileira prevê atitudes como a compostagem, quando a Política Nacional de Resíduos Sólidos, Lei no 12.305/2010 (Brasil, 2010) prevê na definição para a Logística Reversa a destinação final ambientalmente adequada (MMA, 2017). Ainda em relação às medidas políticas neste assunto, segundo fonte da Confederação Nacional do Comércio de
Bens, Serviços e Turismo (CNC, 2011) existe um Projeto de Lei (PLC no 612/2007) aguardando Parecer do Relator na Comissão de Meio Ambiente e Desenvolvimento Sustentável (CMADS) na Câmera dos Deputados. Enquanto este projeto não avança, as capitais do País vêm criando e regulamentando medidas capazes de amenizar o consumo exagerado e o uso frequente das sacolas, com exceção das capitais Belém, Boa Vista, Porto Velho e Rio Branco.

A tendência é o surgimento de um tipo de consumidor que começa a se preocupar com os impactos de seu padrão de consumo na natureza. Esse novo consumidor foi denominado consumidor ecologicamente consciente (ou verde) e seu comportamento está baseado no seu procedimento de compra (Bedante e Slongo, 2004; Vidal, 2012).

Diante do exposto, este trabalho tem por objetivo alcançar um entendimento mais profundo de como está a participação da população do Distrito Federal e seus estabelecimentos diante de mais uma proposta de mudança dos padrões de consumos ditados por atitudes mais sustentáveis visando a entender e avaliar a política ambiental adotada e a prática de consumo. Esperamos demonstrar com este estudo a importância da observação sobre a exploração indevida dos recursos naturais, a devastação, os movimentos ambientais iniciados na década de 70 e o padrão de consumo existente nos dias de hoje.

\section{Material e métodos}

0 instrumento adotado para atingir os objetivos deste trabalho foi o questionário, que foi aplicado a clientes avaliando quesitos sobre o comportamento em relação a transporte das compras, consciência ambiental e comportamento quanto ao lixo doméstico apenas com questões objetivas. Outro questionário foi aplicado aos gerentes de supermercado, que abordava a política ambiental da 
empresa em relação às sacolas plásticas e demais alternativas para o cliente, neste caso com perguntas objetivas $\mathrm{e}$ subjetivas.

Foram observados a idade, a escolaridade, o gênero e a região administrativa que habitavam, no momento da entrevista. Tais requisitos se tornaram obsoletos para o estudo já que o comportamento consumista se tornou prioridade na análise. Foram entrevistadas 66 pessoas no Distrito Federal, de forma aleatória, no ano de 2012. Os locais escolhidos para entrevista foram supermercados, bares e residências, localizados nas Regiões Administrativas de Taguatinga, SIA, Ceilândia e ainda o Plano Piloto.

\section{Resultados e discussão}

A abordagem inicial foi realizada sem a questão ambiental, no sentido de analisar a consumo exercido pelo entrevistado em seu dia-a-dia. De fato, a maioria tem demonstrado aproveitar o produto (as "sacolinhas") oferecido gratuitamente pelos estabelecimentos comerciais. Em seguida a questão ambiental foi introduzida no sentido de fazer o entrevistado observar se pratica, em seu cotidiano, atitudes sustentáveis. A partir desses dados também é perceptível a consciência ambiental do entrevistado, de forma que $100 \%$ acreditam na poluição do meio ambiente por meio das sacolas plásticas descartadas de modo aleatório.

Quando os entrevistados foram perguntados sobre a disponibilidade em utilizar sacolas plásticas distribuídas gratuitamente nos supermercados, $100 \%$ deles usam ou já usaram as sacolas plásticas do tipo comum, distribuídas gratuitamente nos supermercados.

Em relação ao pagamento das sacolas plásticas biodegradáveis vendidas na ausência das sacolas gratuitas (Figura 1), mais de $80 \%$ dos entrevistados não se dispõe a pagar pelas sacolas vendidas nos estabelecimentos comerciais em caso da interrupção do oferecimento gratuito de sacolinhas.

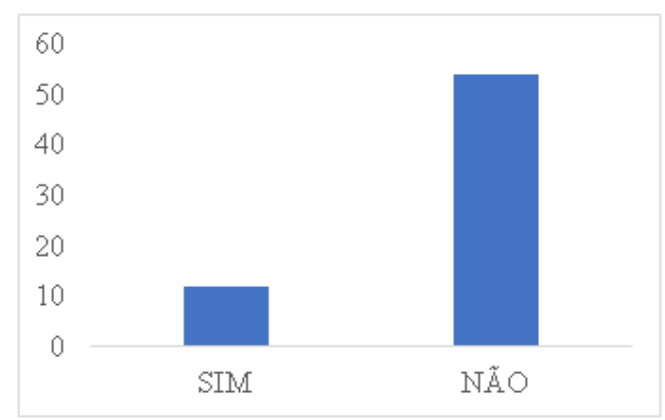

Figura 1. Resultado da pergunta a 66 entrevistados quanto à disponibilidade em pagar por sacolas plásticas biodegradáveis vendidas em supermercados na falta das "sacolinhas" gratuitas.

Em relação ao questionamento quanto a existência da percepção da questão ambiental no cotidiano dos entrevistados, $100 \%$ acreditam que a sacola plástica pode poluir o meio ambiente entendendo o impacto que a mesma pode causar, ainda que a afirmação se contrarie à prática, se confrontada aos resultados obtidos na Figura 1, onde o brasiliense rejeita a possibilidade de pagar pela sacolinha biodegradável que se decompõe mais rapidamente que a sacola tradicional.

Quando o entrevistado foi questionado a respeito do meio em que os produtos adquiridos podem ser transportados do estabelecimento comercial ao seu destino, $90 \%$ admite que usariam meios diferentes da sacola plástica tradicional e gratuita (Figura 2).

Detalhando a Figura 2, foi analisado qual meio de transporte dos produtos adquiridos no comércio teria mais aceitação pelo consumidor, como medida alternativa às sacolas comuns. 0 resultado demonstra que $33 \%$ dos entrevistados adeririam aos sacos biodegradáveis e $20 \%$ às caixas de papelão (Figura 3), comprovando as alternativas frequentemente disponibilizadas nos supermercados e utilizadas pelos moradores do Distrito Federal. 


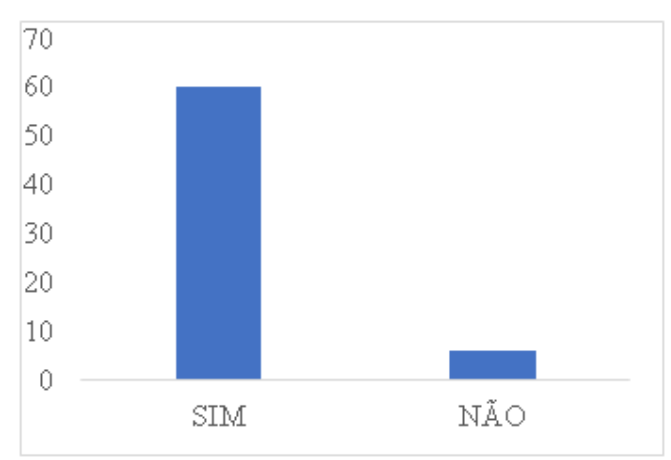

Figura 2. Resultado da pergunta a 66 entrevistados quando a disponibilidade em utilizar meios de transporte diferente da sacola tradicional e gratuita.
Seguindo para a terceira parte da análise, onde o entrevistado é questionado a respeito dos seus hábitos domésticos, foi analisada a forma de armazenamento do lixo produzido em suas residências. A sacola plástica comum e o saco plástico específico para armazenamento de lixo são os mais usados, com mais da metade dos entrevistados afirmando o descarte de lixo todos os dias (Figura 4) o que ressalta a necessidade de recolhimento diário no Distrito Federal.

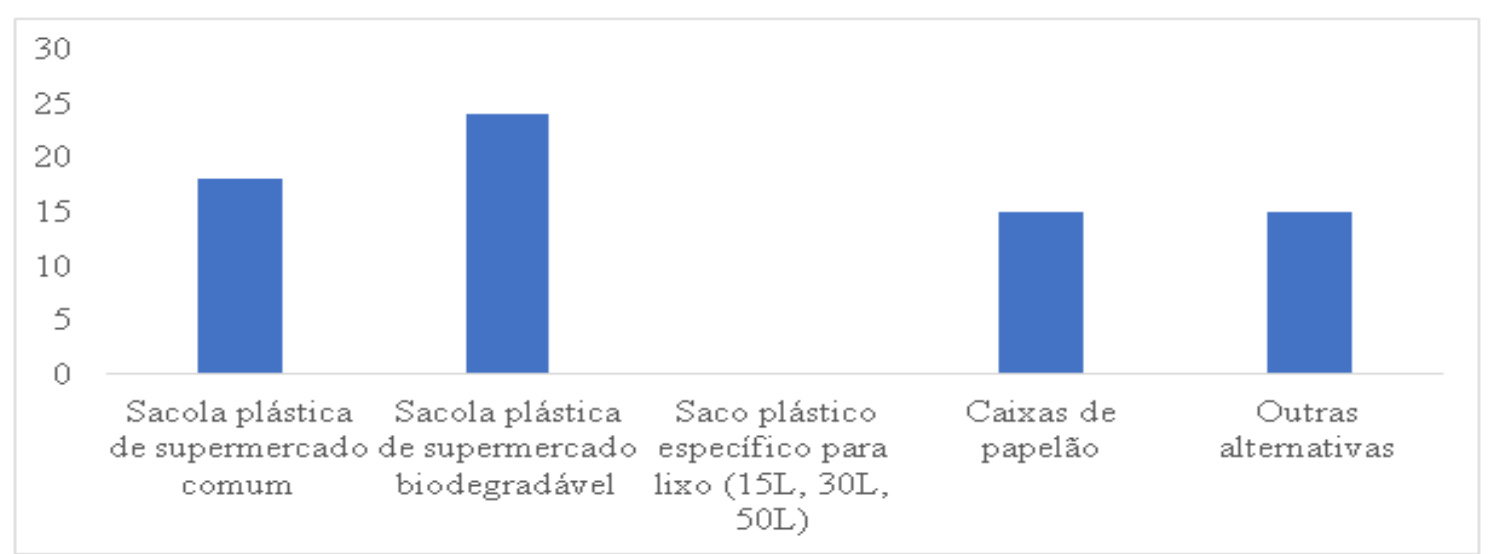

Figura 3. Alternativas mais aceitas por 66 entrevistados em substituição às sacolas plásticas comuns como forma de armazenamento de compras.

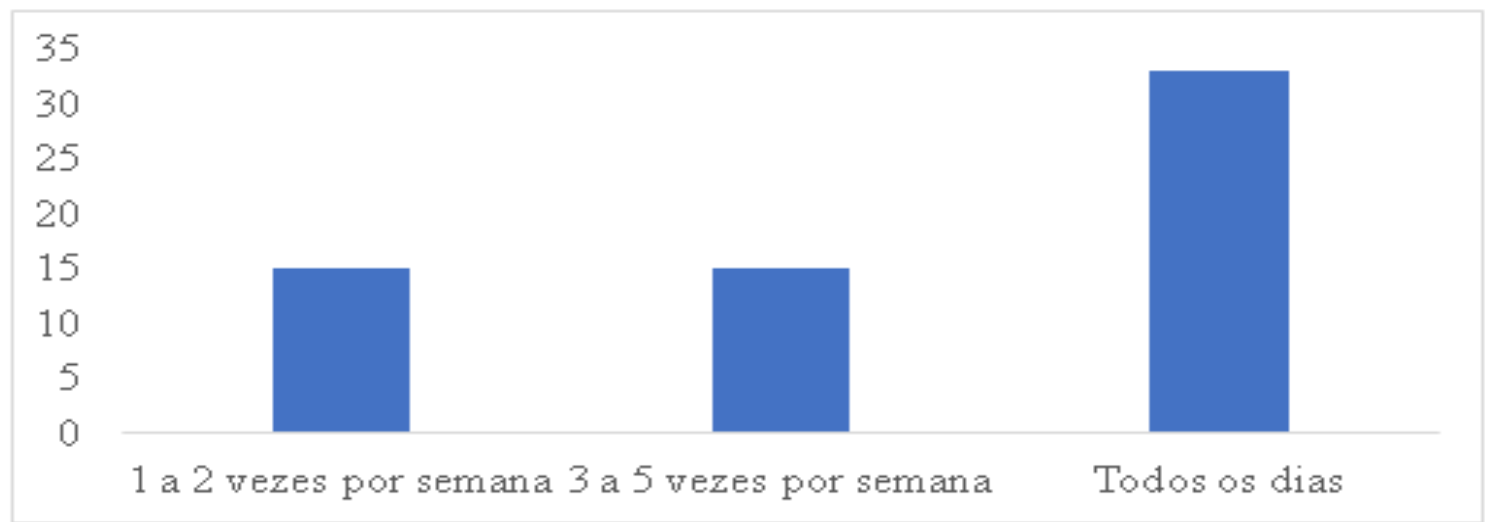

Figura 4. Produção e descarte de lixo doméstico de 66 entrevistados. 
Quanto à preocupação dos entrevistados em ações de reciclagem (Figura 5), mais de $65 \%$ dos entrevistados dizem não se preocupar em destinar o lixo para reciclagem ou reutilização. Tal dado demonstra a falta de sensibilização ambiental do morador do Distrito Federal em relação à produção e destinação de lixo do lixo doméstico. Vale ressaltar que no ano em que a coleta de dados, 2012, a coleta seletiva e a separação do lixo seco e orgânico ainda eram facultativas.

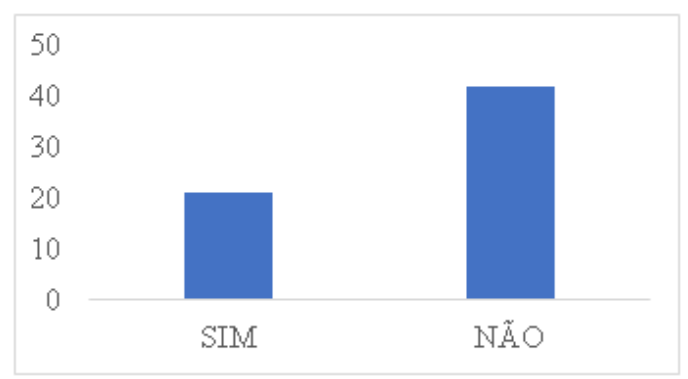

Figura 5. Hábito do consumidor em separar o lixo doméstico para a reciclagem.

0 último quesito deste trabalho diz respeito a curiosidade do brasiliense em conhecer ou visitar uma cooperativa de reciclagem. 0 resultado mostra 0 desinteresse por parte dos entrevistados já todos declararam nunca ter ido a uma cooperativa. Existem cerca de 32 cooperativas distribuídas pelas cidades satélites do Distrito Federal.

Por meio dos dados obtidos percebe-se que o morador do Distrito Federal é um poluidor consciente da sua falta de hábitos ambientais. Entende temas relacionados à degradação e a sustentabilidade, mas não se preocupa em buscar ou praticar a mudança de hábitos para reverter o quadro de desperdício e produção de lixo produzidos atualmente.

0 estudo previu também a realização de questionário (Anexo 2) com os responsáveis por alguns dos supermercados localizados no Distrito
Federal. As redes Atacadão, Pão de Açúcar, Leroy Merlyn, Super Adega e Carrefour foram visitadas, mas nenhum dos responsáveis se prontificaram a responder a pesquisa para 0 desenvolvimento deste projeto. Isso mesmo levando em consideração que esses mercados já desenvolvem alguma política de economia de sacolas plásticas ou adotam sacolas ecologicamente corretas para distribuição ou venda.

Ainda que haja um desinteresse da população, existem cerca de 22 cooperativas distribuídas pelas cidades satélites do Distrito Federal. São cadastradas no Serviço de Limpeza Urbana (SLU) e recolhem o lixo da cidade. Também realizam o trabalho de coleta seletiva e dividem o material coletado entre as cooperativas de reciclagem, de forma igualitária (SLU, 2018).

Além disso, atualmente existe um sistema de implantação de Logística Reversa no Brasil, por meio de acordo setorial assinado em 2015, pelo Comitê Orientador da Logística Reversa, do Ministério do Meio Ambiente, que visa garantir a destinação final ambientalmente adequada das embalagens. Essas podem ser compostas de papel e papelão, plástico, alumínio, aço, vidro, ou ainda pela combinação destes materiais, como as embalagens cartonadas longa vida, por exemplo.

$$
\text { A primeira fase de }
$$
implementação do sistema terá duração de 24 meses. Até o final desse período, o sistema deverá garantir a destinação final ambientalmente adequada de, pelo menos, 3.815,081 t de embalagens por dia.

O acordo contempla apoio a cooperativas de catadores de materiais recicláveis e parcerias com o comércio para a instalação de pontos de entrega voluntária. Ele também prevê a possibilidade de fechamento de acordos entre os serviços públicos de limpeza urbana e manejo de resíduos sólidos municipais e as entidades signatárias. Inicialmente ocorrerá nas cidades e 
regiões metropolitanas de Belo Horizonte, Cuiabá, Curitiba, Distrito Federal, Fortaleza, Manaus, Natal, Porto Alegre, Recife, Rio de Janeiro, Salvador e São Paulo. Já a segunda fase de expansão deverá estabelecer novas metas quantitativas bem como prever a expansão dos sistemas para cidades além das previstas inicialmente (MMA, 2017).

\section{Conclusão}

0 estudo permitiu compreender que a sacola plástica não pode ser vista como uma "vilã". A questão é o consumo de forma excessiva, exagerada, sem que haja um comportamento consciente por parte da população humana. Sua produção gera elevado custo ambiental, sendo necessário um grande consumo de recursos naturais não-renováveis, dejetos líquidos, emissões de gases tóxicos e do efeito estufa. Depois de usadas ainda são descartadas incorretamente causando sérios danos ambientais, como impermeabilização de solos, entupimento de bueiros, e ainda, são jogadas em matas e oceanos, causando a morte de animais e a poluição desses ambientes.

Percebe-se ainda a existência de esforços de diversos países, em amplitude política na tentativa de amenizar o uso desenfreado das sacolas plásticas ou até mesmo proibir a sua utilização. Sugere-se que a capital do país incorpore de forma efetiva, políticas voltadas para minimização de geração de resíduos, fortalecer o consumo consciente e, sobretudo, a disposição final adequada dos resíduos. Sugere-se ainda a incorporação da Educação Ambiental como matéria obrigatória na Educação Básica dos estudantes do Distrito Federal e até mesmo do País, a fim de trabalhar o comportamento ambiental das futuras gerações, visando a diminuição do consumo, a redução do lixo produzido individualmente e o aumento numérico da reutilização e reciclagem de materiais. Desenvolver um olhar crítico e consciente é o primeiro passo para transformação de hábitos.

0 consumo sem exageros leva em consideração o impacto individual de um produto, portanto, levar sacola retornável ao supermercado ao invés de trazer "seis plásticas" para casa, recusar sempre que possível, reduzir o consumo, reutilizar a matéria-prima são ações possíveis e fáceis de serem realizadas e que podem trazer o impacto positivo que tanto se espera na tentativa de amenizar a problemática. Inserir atitudes responsáveis aos hábitos de vida de um indivíduo gera qualidade de vida a toda a sociedade.

\section{Conflito de interesses}

As autoras declaram não haver conflito de interesses.

\section{Referências}

Bedante, G.; Slongo, L. A. 0 comportamento de consumo sustentável e suas relações com a consciência ambiental e a intenção de compra de produtos ecologicamente embalados. Porto Alegre: ANPAD, 2004. Disponível em: <http://www.anpad.org.br/ admin/pdf/ema2004-143.pdf>. Acesso em: 15 abr. 2018.

Brasil. Lei no 12.305, de 2 de agosto de 2010. Institui a Política Nacional de Resíduos Sólidos; altera a Lei $\mathrm{n}$ - 9.605, de 12 de fevereiro de 1998; e dá outras providências. Disponível em: <http://www.planalto.gov. br/ccivil_03/_Ato2007-2010/2010/Lei/ L12305.htm>. Acesso em: 10 out. 2018.

Cangemi, J. M.; Santos, A. M.; Claro Neto, S. Biodegradação: uma alternativa para minimizar os impactos decorrentes dos resíduos plásticos. Química Nova na Escola, v. 22, p. 17-21, 2005.

CNC - Confederação do Comércio de Bens, Serviço e turismo. Veja como está a legislação sobre as sacolas plásticas no Brasil. 2011. Disponível em: <http://cnc.org.br/noticias/ veja-como-esta-legislacao-sobre-sacolasplasticas-no-brasil>. Acesso em: 23 jun. 2018. Crespo, S. A indústria do plástico reage à campanha "Saco é um saco". 2010. Disponível em: <https://www.akatu.org.br/noticia/a- 
industria-do-plastico-reage-a-campanhasaco-e-um-saco/>. Acesso em: 23 jun. 2017.

Fabro, A. T.; Lindemann, C.; Vieira, S. A. Utilização de sacolas plásticas em supermercados. Revista Ciências do Ambiente On-Line, v. 3, n. 1, p. 15-23, 2007. Disponível em: <http://sistemas.ib.unicamp. br/be310/nova/index.php/be310/article/vi ew/70>. Acesso em: 10 out. 2018.

Lima, A.; Lima, I.; Santos, A.; Silva, V. Produção de polímeros naturais e plásticos biodegradáveis utilizando amido. Anais do 53o Congresso Brasileiro de Química, 2013. Disponível em: <http://www.abq.org.br/ cbq/2013/trabalhos/14/3484-13960.html>. Acesso em: 23 jun. 2018.

Lima, P. Sacola plástica é uma das maiores vilãs do meio ambiente. 2016. Disponível em: <http://www12.senado.leg.br/noticias/mate rias/2016/04/19/sacola-plastica-e-uma-dasmaiores-vilas-do-meio-ambiente>. Acesso em: 23 jun. 2017.

MMA - Ministério do Meio Ambiente. Compostagem. Disponível em <http://www.mma.gov.br/estruturas/secex consumo/_arquivos/compostagem.pdf>.

Acesso em: 23 ago. 2018.

MMA - Ministério do Meio Ambiente. Logística reversa. 2017. Disponível em: <http://sinir.gov.br/web/guest/logisticareversa>. Acesso em: 23 jun. 2018.

Oliveira, L. L.; Lacerda, C. S.; Alves, I. J. B. R.; Santos, E. D.; Oliveira, S. A.; Batista, T. S. A. Impactos ambientais causados pelas sacolas plásticas: o caso Campina Grande-PB. Revista de Biologia e Farmácia, v. 7, n. 1, p. 88-104, 2012.

Piatti, T; Rodrigues, R. Plásticos: características, usos, produção e impactos ambientais. Maceió: UFAL, 2005. Disponível em: <http://www.usinaciencia.ufal.br/ multimidia/livros-digitais-cadernostematicos/Plasticos_caracteristicas_usos_ producao_e_impactos_ambientais.pdf $>$.

Acesso em: 25 ago. 2018.
Saldanha, L. J. História do plástico. 2011. Disponível em: <http://www.nossofuturo roubado.com.br/portal/aditivos-

plastificantes/historia-do-plastico>. Acesso em: 23 maio 2018.

Santos, A. S. F; Freire, F. H. O; Costa, B. L. N.; Manrich, S. Sacolas plásticas: destinações sustentáveis e alternativas de substituição. Polímeros, $\quad$ v. $22, \quad$ n. 3, 2012. https://doi.org/10.1590/S0104-142820120 05000036

Senado Federal. Sacola plástica é uma das maiores vilãs do meio ambiente. 2016. Disponível em: <https://www12.senado. leg.br/noticias/materias/2016/04/19/sacol a-plastica-e-uma-das-maiores-vilas-do-meioambiente>. Acesso em: 25 abr. 2018.

SLU - Serviço de Limpeza Urbana do Distrito Federal. Cooperativas de catadores. 2018. Disponível em: <http://www.slu.df.gov.br/ cooperativas-de-catadores/>. Acesso em: 23 abr. 2018.

Viana, B. M. Sacolas plásticas: aspectos controversos de seu uso e iniciativas legislativas. Biblioteca da Câmara dos Deputados. 2010. Disponível em: <http://www2.camara.gov.br/documentose-pesquisa/publicacoes/estnottec/tema14/ 2009_11646.pdf>. Acesso em: 23 jun. 2018.

Vidal, L. A. Marketing ambiental e consumo sustentável: a tendência de empresários e consumidores rumo ao mercado sustentável. Brasília: Centro Universitário de Brasília, 2012. (Monografia de Curso de PósGraduação latu sensu). Disponível em: <https://repositorio.uniceub.br/jspui/handl e/235/7743>. Acesso em: 23 jun. 2018. 